This item was submitted to Loughborough's Research Repository by the author.

Items in Figshare are protected by copyright, with all rights reserved, unless otherwise indicated.

\title{
Processing of cellular ceramics by foaming and in situ polymerisation of organic monomers
}

PLEASE CITE THE PUBLISHED VERSION

PUBLISHER

(c) Elsevier

LICENCE

CC BY-NC-ND 4.0

REPOSITORY RECORD

Sepulveda, P., and J.G.P. Binner. 2007. "Processing of Cellular Ceramics by Foaming and in Situ Polymerisation of Organic Monomers". figshare. https://hdl.handle.net/2134/2681. 


\section{Loughborough University}

This item was submitted to Loughborough's Institutional Repository by the author and is made available under the following Creative Commons Licence conditions.

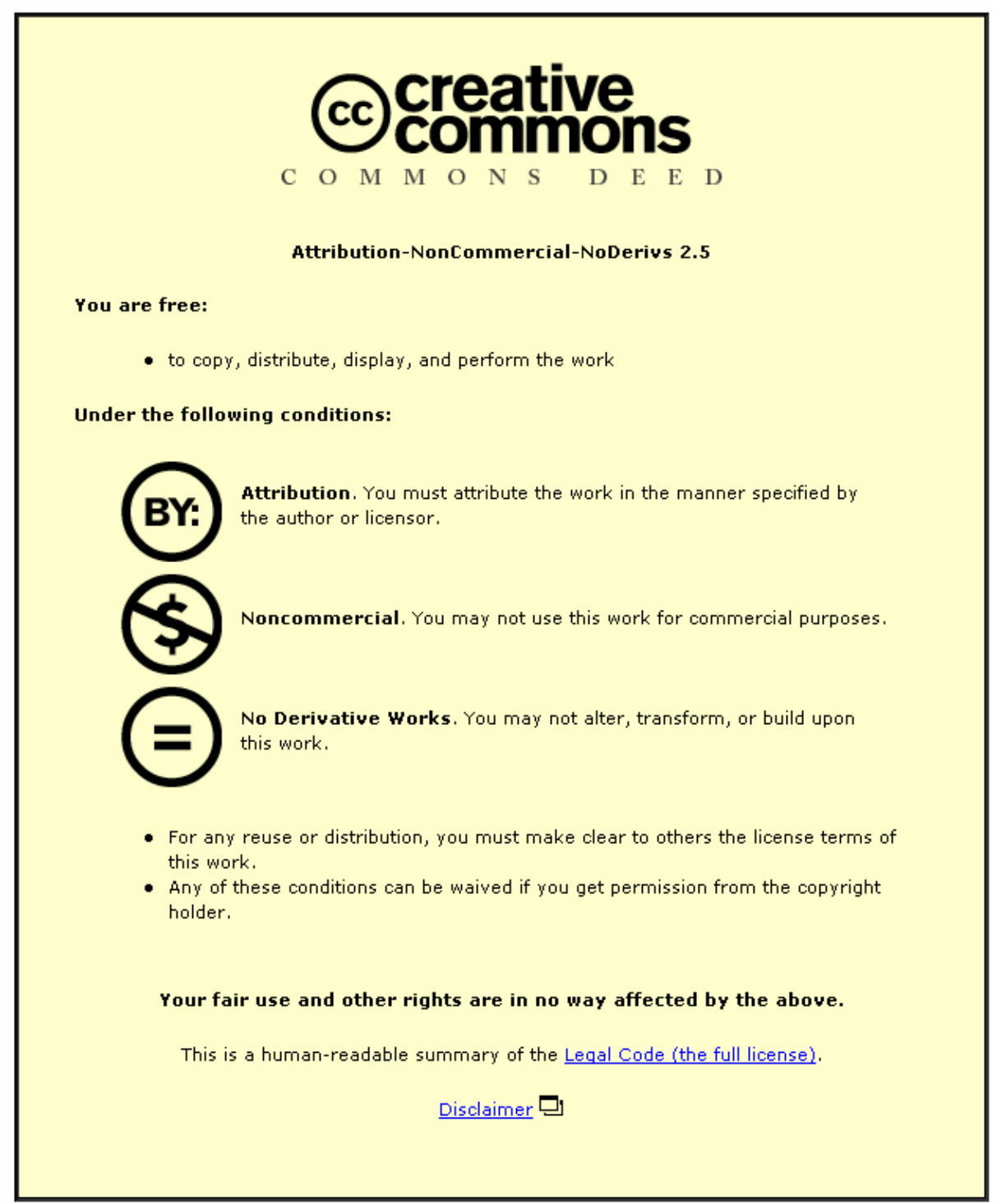

For the full text of this licence, please go to: http://creativecommons.org/licenses/bync-nd/2.5/ 


\title{
PROCESSING OF CELLULAR CERAMICS BY FOAMING AND IN SITU POLYMERISATION OF ORGANIC MOMOMERS
}

\author{
PAI Sepulveda ${ }^{1}$ and JGP Binner \\ Department of Materials Engineering \& Materials Design \\ The University of Nottingham, Nottingham, UK
}

\begin{abstract}
This paper describes studies on a new processing route for fabricating highly porous ceramics. The method is based on the generation of a foam from an aqueous suspension of ceramic powder and the subsequent stabilisation of the structure by in situ polymerisation of organic monomers. The influence of the slip viscosity on the foam volume and stability was determined using concentrated alumina suspensions containing dispersing agents and two commercial foaming agents. The in situ polymerisation of organic monomers led to fast solidification, resulting in strong, porous bodies which could withstand machining. The resulting ceramic foams consisted of a highly interconnected network of spherical cells with densities as low as $6 \%$ of theoretical. The distribution of cell size was dependent both on the density of the specimen produced and on the time for polymerisation onset. The size ranged from approximately $30 \mu \mathrm{m}$ to $600 \mu \mathrm{m}$. Enlargement of cell size to achieve materials of higher permeability was possible through expansion of the foam via pressure reduction before polymerisation. The creation of highly densified struts between the cells led to flexural strengths as high as $26 \mathrm{MPa}$.
\end{abstract}

\section{Introduction}

The increasing interest in porous materials has been associated mainly with their specific properties, such as high surface area, high permeability, low mass, low specific heat and low thermal conductivity. These characteristics are found to be essential for technological applications that can include catalyst supports, filters for molten metals and hot gases, refractory linings for furnaces, and porous implants in the area of biomaterials.

In addition to the composition and mechanical properties of the porous bodies, the cell size and morphology are also important factors that influence the suitability for potential applications.

\footnotetext{
${ }^{1}$ Now with the Departamento de Engenharia de Materiais, Universidada Federal De São Carlos, São Carlos, Brazil. E-mail: p-psi@iris.ufscar.br.
} 
Predominantly closed cell materials are needed for thermal insulation whilst open interconnected materials are required for uses involving fluid transport such as filters and catalysts.

Amongst the various processing methods for fabricating porous ceramics, the four most common can be divided into two groups. The first two approaches lead mainly to porosity in the range of 2-100 $\mathrm{nm}$; they are the incorporation of organic phases that are then eliminated during firing [1] and the partial sintering of ceramics [2]. The other two approaches typically produce cellular pores varying from approximately $50 \mu \mathrm{m}$ to $5 \mathrm{~mm}$; they are the replication of polymer foams by impregnation [3] or CVD coating [4] and the foaming of suspensions[5-7].

This work describes studies on a novel processing route for porous ceramics with a cellular structure. The technique comprises the foaming of aqueous ceramic suspensions containing organic monomers prior to the in situ polymerisation of the foam.

\section{Foaming of Suspensions}

Foams can be produced either by mechanical frothing or by the injection of gases into ceramic suspensions. In most cases the addition of a surfactant is required to stabilise the presence of bubbles. Owing to their molecular configuration, surfactants tend to absorb onto gas-liquid interfaces with a hydrophobic part being expelled from the solvent and a hydrophilic part remaining in contact with the liquid. Through this mechanism, the surfactants can reduce the surface tension of the gas-liquid interfaces and hence stabilise the liquid foams for a limited period of time [8]. A further mechanism is then required to provide a more permanent form of stabilisation.

It should be noted that several transformations in the bubble structure might occur within the interval between foam generation and foam solidification. Some bubbles may shrink and disappear whilst others may coalesce to form larger bubbles. These changes are due to a thinning process of the lamella surrounding the bubbles by mechanisms that include drainage due to gravity, drainage due to capillary action, local depression of surface tension due to hot spots and van der Waals attraction between the surfaces of thin films. Other mechanisms work to resist the thinning. These include: the ability of films to repair differential concentrations of surfactant which may result from disruptions (elasticity); the relatively high viscosity of liquid in the bulk; the electrostatic repulsion between the two sides of a very thin film; and cohesion between the 
absorbed surfactant chains around the film [9]. All changes in the foam structure prior to solidification are important because they influence the final cell size distribution, wall thickness and microstructure of the solid foams. These in turn have a major role in determining properties such as permeability and strength. For example, when the films surrounding bubbles remain intact until solidification, a closed-cell foam is formed. Open-celled foams are produced when the films rupture partially. In extreme cases, excessive film rupture can lead to foam collapse.

\section{Setting of Foamed Suspensions}

The routes and substances currently used for the setting of fluid suspensions, regardless of whether they have been previously foamed, can be classified as follows: drying or freeze-drying of the solvent [10], compositions which can form a gel intrinsically [11], the incorporation of gelling substances such as cellulose derivatives [12] or alginates [13], and the in situ polymerisation of monomers [14-18].

The organic monomers used for the latter route must be soluble in water and retain a high reactivity. Commonly applied types in ceramic systems include methyl methacrylate, butyl acrylate [14], acrylamide [15], and other acrylates [17]. The polymerisation of these vinyl monomers can be brought about by a variety of initiating systems that have a marked influence on the rates at which the reaction proceeds. For example, chemical initiation using systems such as peroxide-amine, as initiator and catalyst respectively, can be very effective in producing fast gelation [19].

In polymerisation, it is common to observe a period of inactivity between the addition of reagents and the actual beginning of the polymerisation reaction. This is known as the induction period or idle time $\left(\mathrm{t}_{\mathrm{i}}\right)$ [20]. In the processing of porous ceramics, the induction period represents the time available for casting of the fluid foam into a mould and for the subsequent changes that take place in bubble structure. Thus, because the induction period allows time for bubble enlargement and lamella thinning, it has an important role in determining the final cell size distribution and strut thickness. It can also result in the presence of flaws in the cell walls if excessive disruption of the films occurs before polymerisation takes place. Good control of the induction time is primarily achieved by altering the concentration of initiator and catalyst; however, other parameters have also been shown to be very important, such as the temperature and $\mathrm{pH}[21]$. 


\section{Experimental Procedure}

\subsection{Foam production}

The process for fabricating the ceramic foams is given by the flowchart in Figure 1 [22]. Aqueous suspensions were prepared containing A16-SG alumina powder ${ }^{2}$ in concentrations ranging from $72-78 \mathrm{wt} \%$, a fixed amount (6.5 $\mathrm{wt} \%$ ) of an acrylate monomer and various concentrations of ammonium polyacrylate dispersing agent. All the slip components were thoroughly mixed and then further homogenised for 15-30 min in a polyethylene ball mill containing alumina cylinders. The suspensions' rheology was evaluated through measurements of shear stress and viscosity at increasing shear rates, from 10 to $1200 \mathrm{~s}^{-1}$, prior to standardising at $80.5 \mathrm{~s}^{-1}$. A V88 Bohlin Viscometer ${ }^{3}$ with a C30 test set up was used for these measurements.

$0.33 \mathrm{wt} \%$ of two different foaming agents, Triton X114 and Tween $80^{4}$, was added, individually, to the alumina suspensions and vigorous stirring was applied in order to generate a foam. This procedure was performed in a sealed vessel under a controlled nitrogen atmosphere. The volume of foam produced was measured against stirring time using $80 \mathrm{~g}$ samples of $74.1 \mathrm{wt} \%$ alumina slip ( $40 \mathrm{ml}$ of unfoamed slip); the foam volume being expressed in $\mathrm{ml}$ and scaled to 100 grams of slip. The rheology of the fluid foams was measured as for the slips and the foam persistence was verified through observation of the mixture in $100 \mathrm{ml}$ measuring cylinders.

The influence of the slip viscosity on the foam volume was examined using slips containing 72 , 75 and $76.5 \mathrm{wt} \%$ alumina whilst in subsequent tests, slips with a comparable viscosity value for all three solids contents were used (approximately $250 \mathrm{mPa}$ s at $80.5 \mathrm{~s}^{-1}$ shear rate).

Setting of the fluid foam was promoted by the in situ polymerisation of the acrylate monomer. Since the polymerisation is intrinsically an exothermic reaction the induction time could be easily evaluated from curves of temperature increase with time. The concentration of these reagents was designed to produce an induction period such that polymerisation was initiated

\footnotetext{
${ }^{2}$ ALCOA SA, Pittsburg, USA

${ }^{3}$ Bohlin Reologi UK Ltd, England

${ }^{4}$ Allied Colloids, Bradford, UK
} 
immediately after casting of the foam into a mould was completed. Subsequent tests were carried out with different induction periods in order to verify the effect on the final cell size.

A procedure was employed to produce foams with cell sizes larger than those obtained directly through foaming. The suspensions were initially foamed as previously described, however only to volumes lower than the final ones desired. Then, within the time allowed by the induction period, the foam was placed in a desiccator and had the pressure reduced using a vacuum pump until the required final volume was achieved. The pressure was held constant until setting of the foam took place.

After polymerisation, all the samples were cooled down to room temperature and removed from the moulds. The specimens were initially dried at room temperature for approximately 24 hours and then in an oven at $110^{\circ} \mathrm{C}$. Firing was performed for 3 hours at $1550^{\circ} \mathrm{C}$ using heating rates of $3^{\circ} \mathrm{C} \min ^{-1}$ up to $300^{\circ} \mathrm{C}$ and then $5^{\circ} \mathrm{C} \min ^{-1}$ up to the sintering temperature.

\subsection{Characterisation of the Foams}

Green bodies were core-drilled and their densities worked out from measurements of their mass and dimensions, both before and after sintering. From the green bodies, samples representing various densities were cut into bars designed to have post-sintering dimensions of approximately $15 \mathrm{~mm} \times 25 \mathrm{~mm} \times 70 \mathrm{~mm}$, for determination of the fired fractured strength by three point bending. A Universal Testing Machine ${ }^{5}$ at a loading rate of $0.6 \mathrm{~mm} / \mathrm{min}$ was used.

The cell size distribution within the foams was obtained using an optical microscope connected to an image analyser. Linear intercept measurements were performed on cross-sectional areas of the foams comprising approximately $60 \mathrm{~mm}^{2}$ areas. Histograms relating the number of cells to the measured cell size were used to retrieve the values of mean cell size and its respective range. The latter was related to a normal distribution standard deviation.

\section{Results and Discussions}

\subsection{Rheology of Suspensions}


Figure 2 shows the effect of dispersant concentration on the viscosity of suspensions at various loadings of alumina powder. The viscosity can be seen to approach a minimum for all solid loadings. This behaviour has been explained elsewhere [23,24].

All the slips prepared in this work revealed a shear thinning or pseudoplastic behaviour. This behaviour is characterised by the decrease in viscosity at increasing shear rates and is typically found in the dispersion of alumina suspensions containing a high percentage of solids. In the fabrication of ceramic foams, a slight pseudoplasticity can favour the generation of the foam since lower viscosities are obtained under shearing, and, under static conditions, can significantly improve the foam stability since the viscosity increase delays the collapse of fluid films around the bubbles.

\subsection{Foaming of Alumina Suspensions}

Figure 3 shows the foam volume versus stirring time for suspensions containing $74.1 \mathrm{wt} \%$ alumina and the two different foaming agents. The foam volume increases gradually up to a maximum after approximately $4 \mathrm{~min}$ of agitation. During this initial stirring period gas is entrained into the suspensions and liquid is drawn around each bubble until a thin film is formed. Initially, the ability of a foaming agent to produce large quantities of foam depends on the surfactant's effectiveness in reducing the surface tension of the solution. Subsequently, the surfactant molecules of the foaming agent move from the interior of the slips toward the newly created surfaces, establishing forces to prevent further thinning. When most surfactant molecules have attached themselves to the gas-liquid interfaces, the stabilisation of new films is no longer possible and the volume increase becomes negligible. Hence, the maximum foam volume is associated with a minimum thickness of film that can sustain a stable foam. Above this level, stirring may continuously generate bubbles; however, they disintegrate almost instantly preventing an increase in the foam value.

Besides the ability to generate high foam volumes, a foaming agent must also be able to produce stable and firm foams. With respect to foam stability, as expected, bubble enlargement occurred at faster rates for less viscous and more highly foamed suspensions. This bubble enlargement is mainly a result of coalescence and coarsening. The coalescence of neighbouring bubbles is a consequence of the displacement of liquid around neighbouring bubbles up to the point that the

\footnotetext{
${ }^{5}$ Mayes, UK
} 
films separating them are so fine that rupture occurs. Coarsening, on the other hand, occurs due to the diffusion of gas. This is driven by differential pressure from smaller to larger bubbles [9]. These two phenomena occur at significantly faster rates in more highly foamed suspensions because of the reduced thickness of the liquid films.

Figure 4 reveals the maximum foam volume generated with suspensions containing from 72 to $78 \mathrm{wt} \%$ alumina and with each solids content suspension being deliberately formulated to have a range of viscosities. It may be seen that the viscosity had little influence on the final foam volume generated except for the lowest solids content slurry. It should be noted that slips of viscosity lower than about $250 \mathrm{mPa}$ s probably led to smaller foam volumes due to the inferior stability of the liquid films created. Meanwhile, the slight decrease in foam volume generated with slips of viscosity higher than $250 \mathrm{mPa}$ s is believed to be attributable to the inability of the mixer used to maintain the required speed levels when stirring the more viscous systems.

The rheology of the foamed slips displayed in Figure 5(a) appears to be typical of pseudoplastic fluids. At the lowest shear rates measured, the foamed systems exhibited viscosity levels of approximately 1.5 Pa s to 2.0 Pa s, whilst the non foamed suspension showed a viscosity of about $0.5 \mathrm{~Pa}$ s. At these low shear rates, the high viscosity of the foams can be attributed to the presence of bubbles and surfactant molecules at the gas-liquid interfaces. These interact with each other to provide resistance to deformation. At the higher shear rates, the foam viscosities attained values that were comparable to the viscosity of the non-foamed slip as a result of foam collapse. This behaviour can be confirmed by the variation of shear stress against shear rate observed in the curves of Figure 5(b). For foamed systems, the shear stress increases with increasing shear rate up to $\sim 600 \mathrm{~s}^{-1}$ followed by a marked decrease above this level. This point is related to the stress level that the liquid films can resist. These results demonstrate that under higher stresses the properties of the wet foams are altered by the measurements themselves. Therefore, in order to compare non-foamed and foamed systems in terms of viscosity, only the measurements performed at the lower shear rates should be considered.

The foam rheology is important because the process involves casting. In common with other casting operations, very fluid systems are required in order to enable easy filling of small details in moulds to allow production of high complexity shapes. The high viscosity characteristics of foamed systems at low shear rates can thus be a critical factor for the production of complex shaped foamed bodies. 


\subsection{Foam Density and Cell Size Distribution}

Figure 6 shows the green and sintered density values of bodies produced from suspensions foamed to different levels. Green densities ranging from 0.18 to $1.09 \mathrm{~g} \mathrm{~cm}^{-3}$ were obtained, leading to post-sintering densities of $7 \%$ to $47 \%$ of the theoretical value (taken as $3.94 \mathrm{~g} \mathrm{~cm}^{-3}$ ). This corresponds to as much as 93\% porosity in the final structure. The linear shrinkage of the foams ranged between $2 \%$ and $4 \%$ during drying. On sintering, the levels of shrinkage were found to be within the limits of approximately $15-20 \%$ and, as expected, increased as the solids content decreased.

The evolution of cell size for foams with a final density of $12 \%$ of theoretical $\left(0.33 \mathrm{~g} \mathrm{~cm}^{-3}\right)$ that were polymerised after various induction times $\left(\mathrm{t}_{\mathrm{i}}\right)$ can be observed in Figure 7. A clear influence on $t_{i}$ can be observed. When polymerisation occurred only $30 \mathrm{~s}$ after foam generation, the foam structure was preserved against excessive bubble enlargement. Thus a narrow cell size distribution was achieved with cell sizes generally in the range of 30-300 $\mu \mathrm{m}$. As the induction time was extended the mean cell size increased and substantially wider cell size distributions were observed.

Polymerisation promoted at a late stage of bubble enlargement is generally undesirable because it can produce low strength materials as a result of flaws originating from disrupted cells. In addition, the longer induction period leads to a broader and less controlled cell size distribution, and so should not be used to produce large cell size foams.

The density plays an important role in the determining the microstructure of the sintered foams, as shown by Figure 8. The foams exhibit approximately spherical cells with no preferred orientation, resulting in isotropic properties. It can also be seen that the cell walls are filled with extra material as the density is increased, leading to a smaller window size and hence thicker struts. Very high density foams exhibit a near closed-cell structure with inter-connectivity reduced to effectively zero. If the density is increased further beyond this point, the only effect is that the struts become thicker.

Figure 9 shows the mean cell sizes and corresponding cell size ranges retrieved from the histograms in Figure 7 for foams of various densities. The mean cell size varies within the limits 
of 50-300 $\mu \mathrm{m}$, with a distribution in the range of 30-600 $\mu \mathrm{m}$, with the larger sizes being found in the lower density structures. These variations in cell size and strut thickness are a direct result of the foaming process. Highly foamed slips have liquid films of reduced thickness and due to the faster drainage, they suffer rapid bubble enlargement. This leads to the final foams containing thinner struts, larger cell and window sizes, and thus being more permeable.

The cell size distribution of foams could be varied independently of the sample density by expanding a fluid foam up to a higher final volume by reducing the pressure present prior to polymerisation. Table 1 shows the results of sintered density and mean cell size for foams expanded from slips containing $71.4 \mathrm{wt} \%$ and $75 \mathrm{wt} \%$ alumina. The expansion led to mean cell sizes within the limits of 250-700 $\mu \mathrm{m}$, with a distribution of 50-2000 $\mu \mathrm{m}$, depending mainly on the magnitude of the volume expanded. Micrographs in Figure 10 show examples of the structure of a non expanded (a) and of an expanded (b) foam with the same density. A variety of permeability levels and porosity ranges may be produced in this manner, greatly increasing the extent of possible applications for these porous ceramics. 


\subsection{Mechanical Strength}

Figure 11 depicts the bending strength of alumina foams as function of the density. As expected, the strength decreases proportionally to the decrease in density owing to the smaller bulk area that is actually submitted to loading in lower density specimens.

The relationship between the foam density and bending strength had a slope of 2.3 in a double log plot. This value differs from the 1.5 value predicted by the model proposed by Gibson et al [25], which is designed to describe the dependence of the properties of open cellular ceramics on the density:

Properties of foam $\propto C\left[\frac{\rho}{\rho_{s}}\right]^{3 / 2}$

where $\mathrm{C}$ is a constant that depends on the geometry of cells, $\rho$ is the foam density and $\rho_{\mathrm{s}}$ is the strut density.

The power dependence of the strength on the relative density obtained in this work shows that the density exerts a more pronounced influence on the strength than that predicted by the model. This is because the model considers foams with constant cell size, whereas in this work the cell size varies with density. Furthermore, variations in strut strength as a result of the variations in density may also have a role in the observed results. Thinner struts in low density foams contain a large number of defects because they derive from thinner films in the liquid foam, which are closer to rupturing. Conversely, the thicker struts in the denser foams, originate from stable, non disrupted films and hence contain fewer defects. Evidence for this came from SEM observations that revealed residual porosity in the struts of some of the lowest density foams produced. Brown et al [26] has also shown that for open-cell ceramics the strut strength can be dependent on strut volume and on the microstructure of the strut.

The problems with low strength levels reported in reticulated foams do not appear in the foams produced in this work. For instance, Lange et al [27] reported tensile strengths no greater than 0.8 MPa for a range of commercial alumina/zirconia products of density ranging from $7 \%$ to $12 \%$. Brezny et al [28] presented values of bending strength varying from $0.5 \mathrm{MPa}$ to $6 \mathrm{MPa}$ when the density increased from $8 \%$ to $24 \%$ for high alumina compositions. Consequently, the higher magnitudes of strength of foams produced in this work, $26 \mathrm{MPa}$ when the density was 
$30 \%$ of theoretical, have been related to the dense struts and less flawed microstructures that are created when polymerisation proceeds rapidly soon after foaming.

\section{Conclusions}

The method of foaming followed by polymerisation studied in the present paper shows high versatility and the ability to produce highly porous green bodies that are comparatively strong and can easily withstand machining. The density of the ceramic foams could be varied by altering the foam volume generated with a given quantity of slip. Cells showed smaller interconnecting windows and larger strut thickness when the density of the specimens was increased. The induction time for polymerisation onset also influenced the cell size distribution since it allowed time for bubble enlargement. In general both the mean cell size and the distribution were broadened. Expansion of the fluid foams prior to polymerisation could be used to generate a large range of cell sizes independently of the density. Cell size was enlarged from 30-600 $\mu \mathrm{m}$ in non expanded foams up to $50-2000 \mu \mathrm{m}$ in expanded foams.

The bending strength varied between $2 \mathrm{MPa}$ and $26 \mathrm{MPa}$ for samples of density ranging from $8 \%$ to $30 \%$ of theoretical density. The higher strength magnitudes obtained for this material, compared to other conventional methods, are due to the less flawed structure and dense struts and walls produced.

\section{Acknowledgements}

All the authors would like to thank Dytech Co, UK, and one of the authors (P. Sepulveda), CAPES, Brazil, for the financial support for this research.

\section{References}

1. Kormarneni, S, Pach L, Pidugu, R, "Porous a-Alumina Ceramics using Boehmite and Rice Flour", Mat Res Soc Symp Proc 371 pp 285-290, 1995.

2. Lehigh, M D, Nettleship, I, "Microstructural Evolution of Porous Ceramics" Mat Res Soc Symp Proc 371 pp 315-320, 1995.

3. $\quad$ Minnear, W P, "Processing of Porous Ceramics", Ceram Trans 26 pp 146-156, 1992.

4. Lin, Y S, Burggraaf, A J, "CVD of Solid Oxides in Porous Substrates for Ceramic Membrane Modification", AIChe Journal 38 [3] pp 445-454, 1992. 
5. Wu, M, Fujiu, T, Messing, G L. "Synthesis of Cellular Inorganic Materials by Foaming Sol-Gels", J Non-Crystalline Solid 121 pp 407-412, 1990.

6. Powell, S J, Evans, J R G, "The Structure of Ceramic Foams Prepared from Polyurethane-Ceramic Suspensions", Mat Manufact Processes 10 [4] pp 757-771, 1995.

7. BASF European Patent Application, "Ceramic Foam", 0330963, 1989.

8. Rosen, M J, "Surfactants and Interfacial Phenomena", $2^{\text {nd }}$ Edition, John Wiley and Sons, pp 277-303, New York 1989.

9. $\quad$ Bikkerman, J J, "Foams", Springer Verlag, New York, 1973.

10. Hohne, J, "Fabrication of Ceramic Components by Low Temperature Injection Moulding and Freeze-Drying", Euro-Ceram II vol 1, Ed Z Giegler, pp 415-421, 1991.

11. Bagwell, R B, Messing, G L, "Critical Factors in Production of Sol-Gel Derived Porous Alumina", Key Engineering Materials, 115, pp 45-64, 1996.

12. Moreno, R, "The Role of Slip Additives in the Tape-Casting Technology", Ceram Bull 71 [11] pp 1647-1657, 1992.

13. Katsuki, H, Kawahara, A, Ichinose, H, "Preparation and Some Properties of Porous Alumina Ceramics Obtained by Gelatination of Ammonium Alginate", J Mat Sci 27 pp 6067-6070, 1992.

14. Grader, G S, Zuri, L, "Tape Casting Slip Preparation by in situ Polymerisation", J Am Ceram Soc 76 [7] pp 1809-1814, 1993.

15. Young, A C, Omatete, O O, Janey, M A, Menchhofer, P A, "Gelcasting of Alumina", $J$ Am Ceram Soc 74 [3] pp 612-618, 1991.

16. Landham R R, Nahass P, Leung, D K, Ungureit M, Rhine W E, Bowen H R, Calvert P D, "Potential use of Polymerisation Solvents and Dispersants for Tape Casting of Ceramics", Ceram Bull 66 [10] pp 1513-1516, 1987.

17. Janney M A, Marietta M, "Methods for Moulding Ceramic Powders", US Patent 4894194, 1990.

18. Omatete, O O, Janney, M A , Strehlow R A, "Gelcasting - A New Ceramic Forming Process", Ceram Bull 70 [10] pp 1641-1649, 1991.

19. Feng, XD, Guo, XQ, Qui, KY, "Study of the Initiation Mechanism of the Vinyl Polymerisation with the System Persulfate/N,N,N',N',-tetramethylethylenediamine", Makromol Chem 189 pp 77-83, 1988.

20. Zhu, S, Hamiliec A, "Kinetics of Polymeric Network Synthesis via Free-Radical Mechanisms - Polmerisation and Polymer Modification", Makromol Chem, Macromol Symp 63 pp 135-182, 1992. 
21. Sepulveda, P, PhD Thesis, "Processing of Cellular Ceramics Synthesised by Gel Casting of Foams", University of Nottingham, 1996.

22. Smith, R, PhD Thesis, "Processing of Engineering Porous Ceramics", University of Nottingham, 1994.

23. Cesarano III, J, Aksay, I A, "Stability of Aqueous a-Alumina Suspensions Stabilised with Polyelectrolytes", J Am Ceram Soc 71 [12] pp 1062-1067, 1988.

24. Hirata, Y, Nishimoto, A, Ishihara, Y, "Effects of Addition of Polyacrylic Ammonium on Colloidal Processing of a-Alumina", J Ceram Soc, Japan, 100 [10] pp 983, 1991.

25. Gibson, L J, Asby, M F, "Cellular Solids, Structure and Properties", Pergamon Press, 1988.

26. Brown, D D, Green, D J, "Investigation of Strut Crack Formation in Open Cell Alumina Ceramics", J Am Ceram Soc 77 [6] 1467-72, 1994.

27. Lange, F F, Miller, K T, "Open-Cell, Low Density Ceramics Fabricated from Reticulated Polymer Substrates", J Am Ceram Soc 70 [4] pp 827-831, 1987.

28. Brenzy, R, Green, D J, "Fracture Behaviour of Open-Cell Ceramics", J Am Ceram Soc 72 [7] 1145-52, 1989. 


\section{List of Figures and Tables}

Fig 1. Flow-chart for production of ceramic foams using the in situ polymerisation of monomers for stabilisation.

Fig 2. Viscosity measured at a shear rate of $80.5 \mathrm{~s}^{-1}$, plotted as function of dispersant concentration for alumina suspensions containing $72 \mathrm{wt} \%$ to $78 \mathrm{wt} \%$ solids.

Fig 3. Foam volume generated with suspensions containing $74.1 \mathrm{wt} \%$ alumina, with three different commercial foaming agents.

Fig 4. Foam volume produced with compositions formulated to have different viscosities.

Fig 5. Flow behaviour of suspensions containing $74.1 \mathrm{wt} \%$ alumina, in a non-foamed state and when foamed to two different levels of $185 \mathrm{ml}$ and $265 \mathrm{ml}$. Plots of (a) viscosity and (b) shear stress against shear rate are shown.

Fig 6. Plots of green and final density, after sintering at $1550^{\circ} \mathrm{C}$ for $3 \mathrm{~h}$.

Fig 7. Histograms of cell size distribution for foams of $0.33 \mathrm{~g} \mathrm{~cm}^{-3}$ sintered density $(12 \%$ dense) and produced with induction time of (a) 30 s, (b) $90 \mathrm{~s}$ and (c) $200 \mathrm{~s}$.

Fig 8. SEM micrographs of ceramic foams with sintered densities of (a) $10 \%$, (b) $15 \%$, (c) $20 \%$ and (d) $40 \%$ of theoretical. All micrographs taken at a magnification of x 55 .

Fig 9. Cell size data retrieved from cell size histograms of ceramic foams at various densities showing mean cell size and cell size ranges.

Fig 10. SEM micrographs illustrating the cell size enlargement produced by expansion of foamed suspensions. In (a) a non expanded foam and (b) an expanded foam, both with relative density of $9 \%$. Both micrographs taken at a magnification of x 90 .

Fig 11. Flexural strength of alumina foams produced with $71.4 \% \mathrm{wt} \%$ solids, against the relative density.

Table 1. The consequence of reducing pressure during foaming on mean cell size and relative density. 


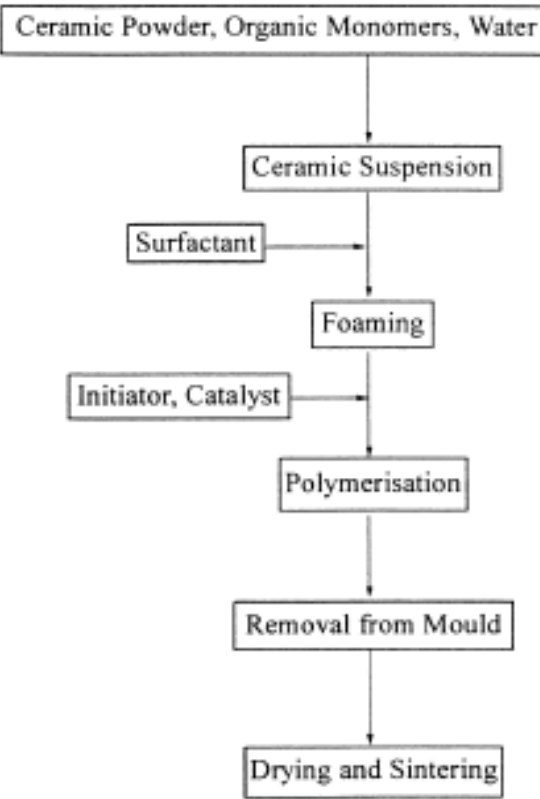

Fig 1

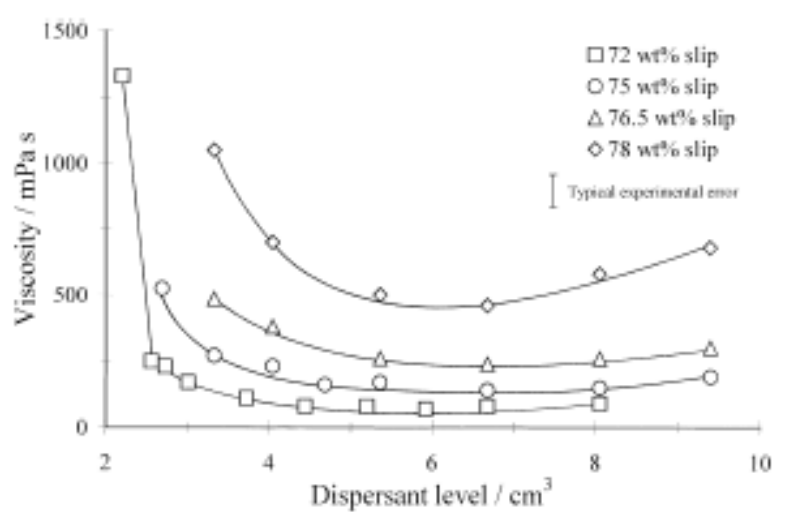

Fig 2 


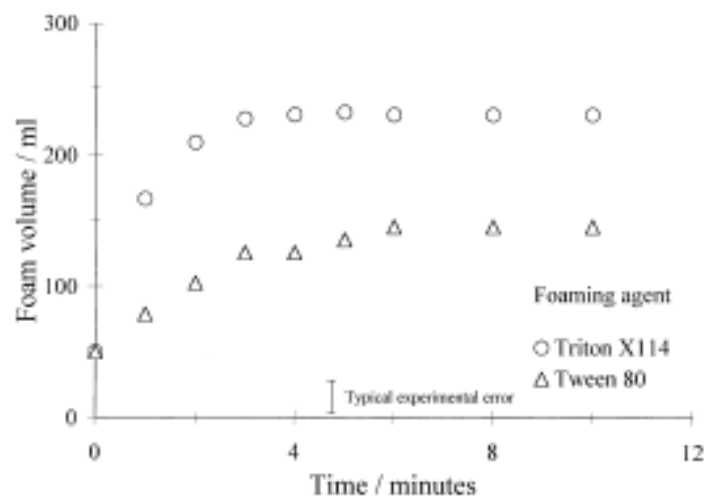

Fig 3

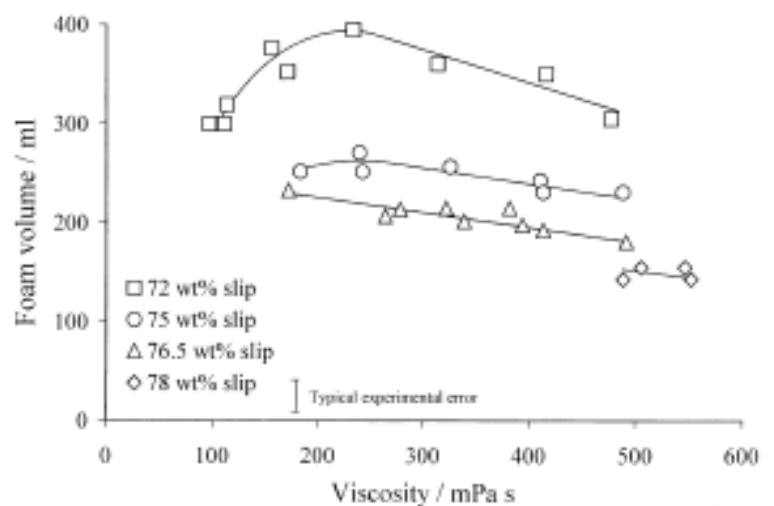

Fig 4 

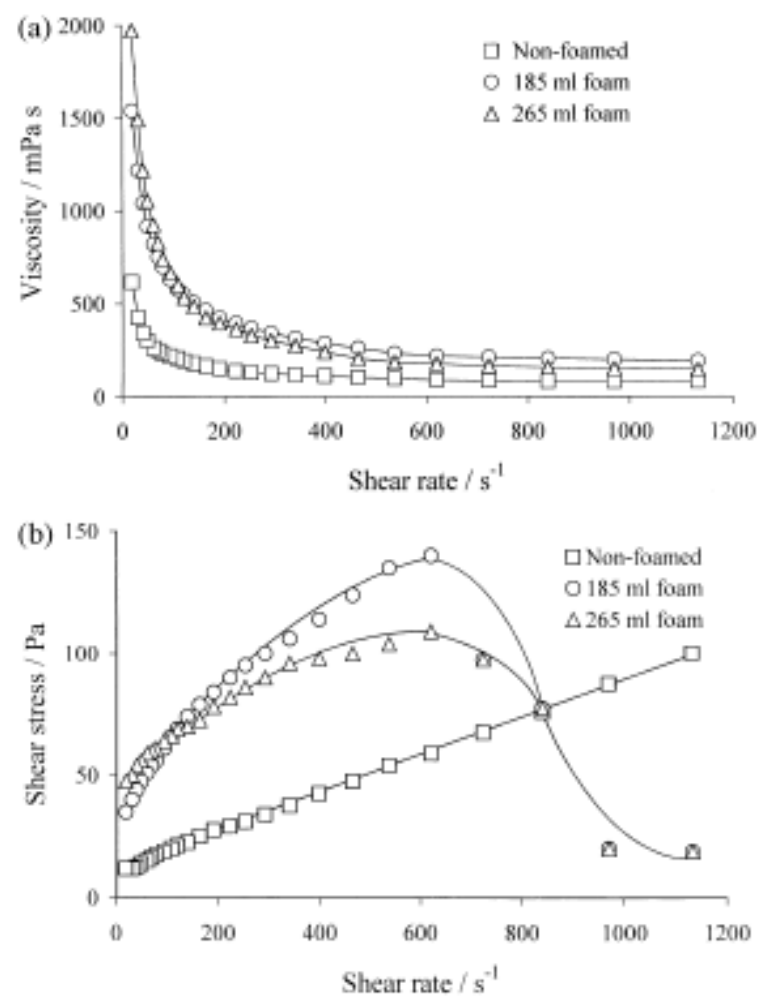

Fig 5

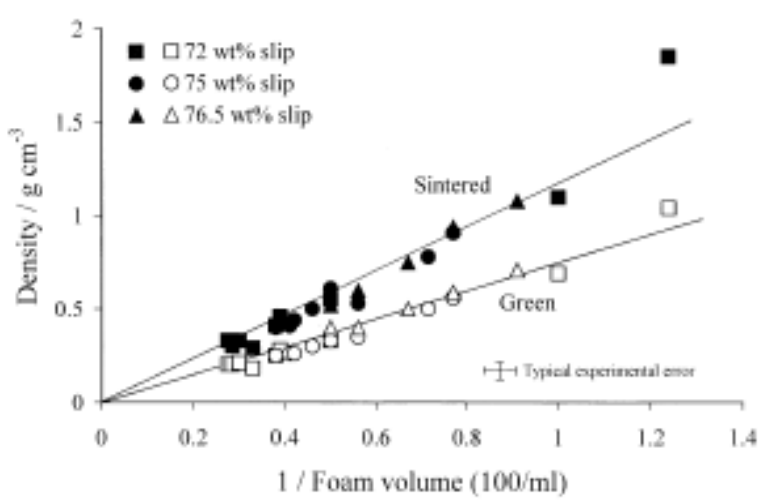

Fig 6 


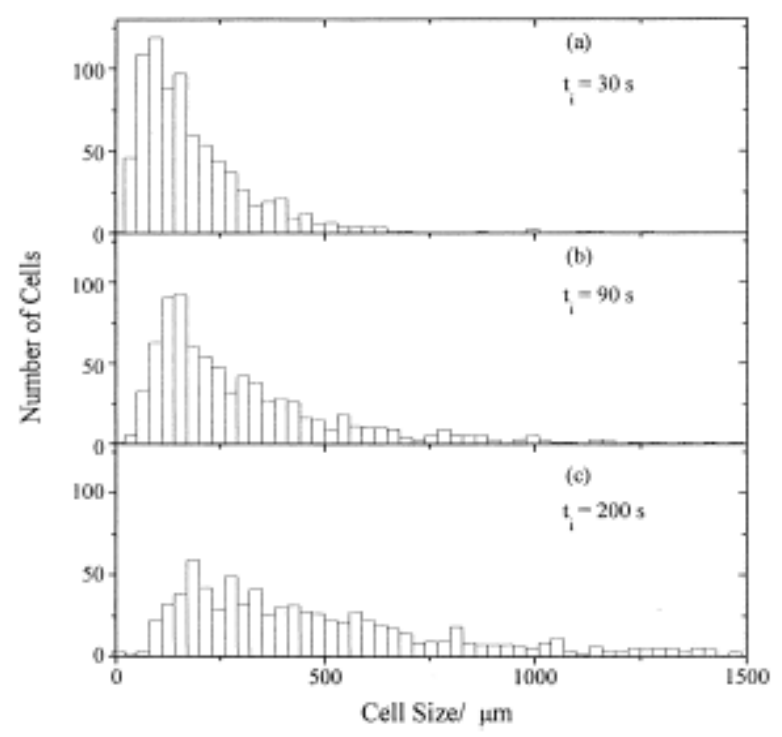

Fig 7

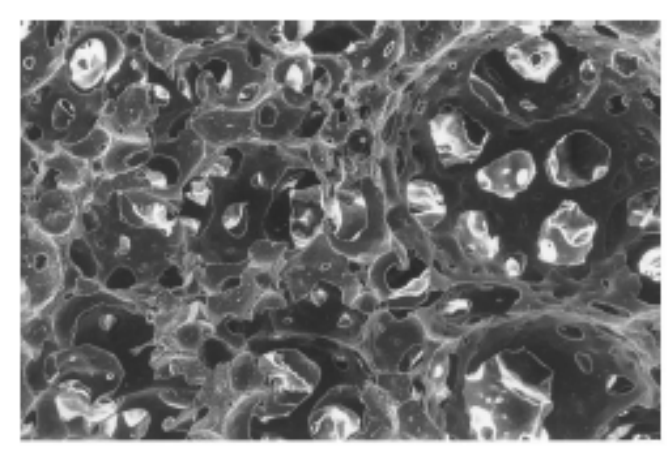

(a)

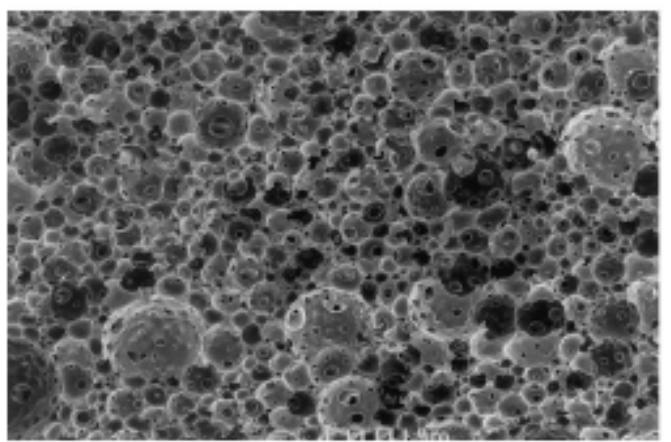

(c)

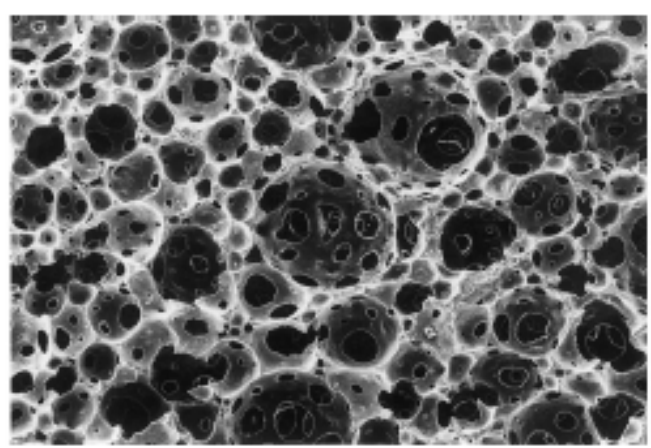

(b)

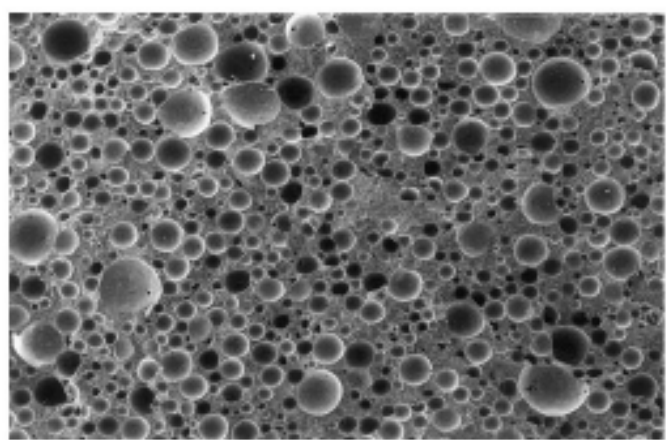

(d)

Fig 8 


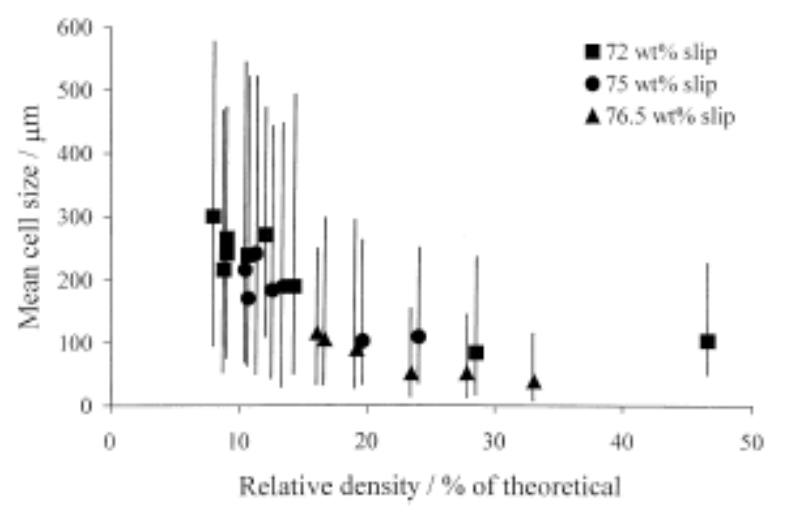

Fig 9

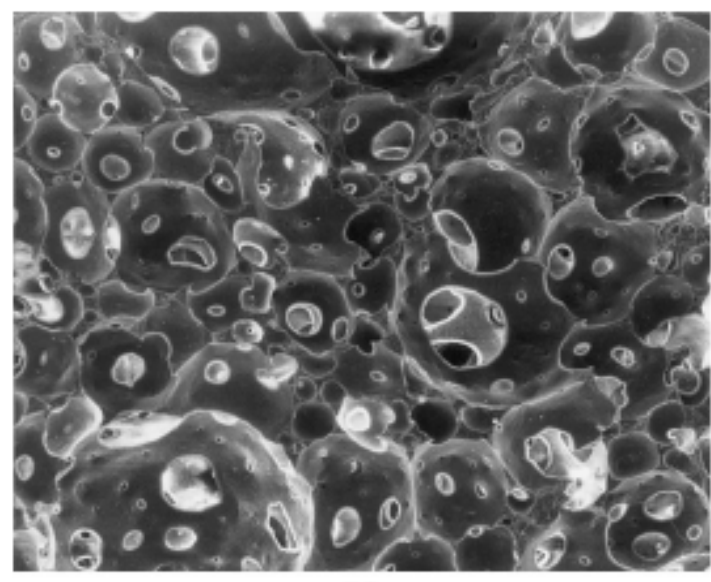

(a)

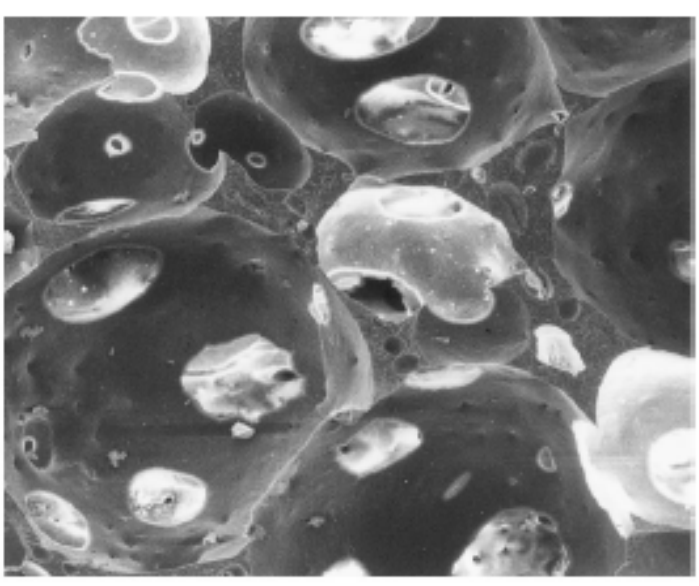

(b)

Fig 10 


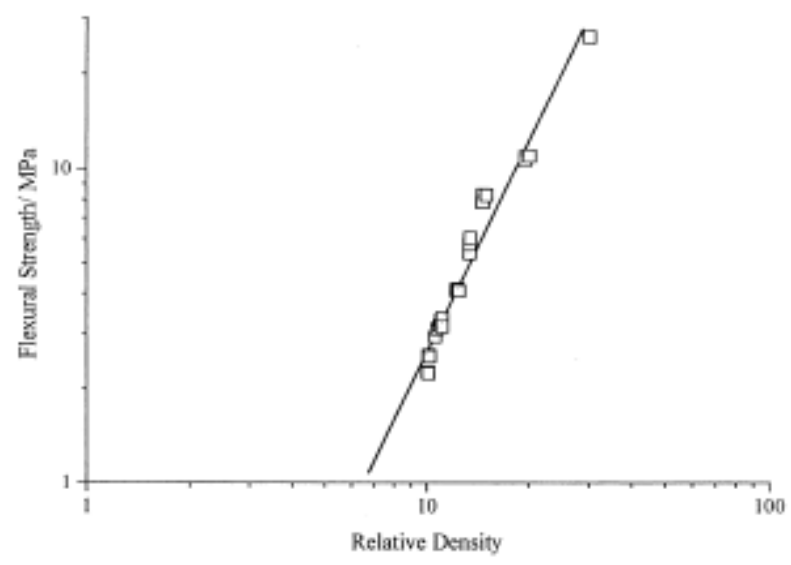

Fig 11

\begin{tabular}{|c|c|c|c|c|c|}
\hline $\begin{array}{c}\text { Slip composition / wt \% } \\
\text { alumina }\end{array}$ & $\mathbf{V}_{\mathbf{o}} / \mathbf{m l}$ & $\mathbf{V}_{\mathbf{f}} / \mathbf{m l}$ & $\Delta \mathbf{V} / \mathbf{m l}$ & $\begin{array}{c}\text { Relative } \\
\text { density / \% }\end{array}$ & $\begin{array}{c}\text { Mean cell } \\
\text { size / } \boldsymbol{~ m}\end{array}$ \\
\hline 71.4 & 115 & 415 & 300 & 6.2 & 540 \\
71.4 & 140 & 415 & 275 & 6.3 & 560 \\
71.4 & 220 & 430 & 210 & 6.4 & 470 \\
71.4 & 105 & 325 & 220 & 8.7 & 700 \\
71.4 & 125 & 325 & 200 & 8.9 & 630 \\
71.4 & 135 & 310 & 175 & 9.0 & 520 \\
75 & 140 & 330 & 190 & 8.7 & 390 \\
75 & 190 & 330 & 140 & 8.7 & 370 \\
75 & 115 & 325 & 210 & 9.1 & 360 \\
75 & 125 & 325 & 200 & 9.1 & 550 \\
75 & 210 & 330 & 120 & 16.6 & 280 \\
75 & 190 & 300 & 110 & 16.7 & 260 \\
\hline
\end{tabular}

Table 1 